\title{
A consensus statement on the renal monitoring of Australian patients receiving tenofovir based antiviral therapy for HIV/HBV infection
}

Stephen G Holt ${ }^{1 *}{ }^{*}$, David M Gracey ${ }^{2 \dagger}$, Miriam T Levy ${ }^{3 \dagger}$, David W Mudge ${ }^{4 \dagger}$, Ashley B Irish ${ }^{5 \dagger}$, Rowan G Walker ${ }^{6 \dagger}$, Richard Baer ${ }^{7 \dagger}$, Jacob Sevastos ${ }^{8 \dagger}$, Riaz Abbas $^{9+}$ and Mark A Boyd ${ }^{10 \dagger}$

\begin{abstract}
A number of antiviral agents used against Human Immunodeficiency Virus (HIV) infection and hepatitis B virus (HBV) mono or co-infection have been associated with real nephrotoxicity (including tenofovir disoproxil fumarate (TDF), atazanavir, indinavir and lopinavir) or apparent changes in renal function (e.g. cobicistat, ritonavir, rilpivirine and dolutegravir). Patients with HIV are at higher risk of acute and chronic renal dysfunction, so baseline assessment and ongoing monitoring of renal function is an important part of routine management of patients with HIV. Given the paucity of evidence in this area, we sought to establish a consensus view on how routine monitoring could be performed in Australian patients on ART regimens, especially those involving TDF. A group of nephrologists and prescribers (an HIV physician and a hepatologist) were assembled by Gilead to discuss practical and reasonable renal management strategies for patients particularly those on TDF-based combination regimens (in the case of those with HIV-infection) or on TDF-monotherapy (in the case of HBV-mono infection). The group considered which investigations should be performed as part of routine practice, their frequency, and when specialist renal referral is warranted. The algorithm presented suggests testing for serum creatinine along with plasma phosphate and an assessment of urinary protein (rather than albumin) and glucose.

Here we advocate baseline tests of renal function at initiation of therapy. If creatinine excretion inhibitors (e.g. cobicistat or rilpivirine) are used as part of the ART regimen, we suggest creatinine is rechecked at 4 weeks and this value used as the new baseline. Repeat testing is suggested at 3-monthly intervals for a year and then at least yearly thereafter if no abnormalities are detected. In patients with abnormal baseline results, renal function assessment should be performed at least 6 monthly. In HBV mono-infected patients advocate that a similar testing protocol may be logical.
\end{abstract}

Keywords: HIV, Hepatitis B, Tenofovir, Renal failure, Fanconi syndrome, Monitoring

\section{Review}

\section{Introduction}

Human immunodeficiency virus (HIV) infection has now become a chronic disease for most patients treated with antiretroviral therapy (ART) [1]. The improvement in prognosis has however unmasked a vulnerability to lifestyle and metabolic diseases like diabetes and hypertension, and has highlighted the potential for rare side effects

\footnotetext{
* Correspondence: steve.holt@mh.org.au

${ }^{\dagger}$ Equal contributors

${ }^{1}$ The Royal Melbourne Hospital and Faculty of Medicine University of Melbourne, 300 Grattan St, Parkville, Melbourne, VIC 3050, Australia Full list of author information is available at the end of the article
}

of ART, including the nephrotoxic potential of some drugs [2]. HIV-infected individuals have higher risks of both acute and chronic kidney disease (CKD) [3-6] than the general population. Thus the monitoring of renal function and identification and treatment of risk factors for CKD are important elements of HIV management. For most patient groups, this can be done in line with existing guidelines, such as the Kidney Health Check [7]. However in the monitoring of patients on some antiretroviral agents there are key differences to this routine review. A recent Australian study found that there is room to improve the management of renal disease in HIV-infected patients [8].

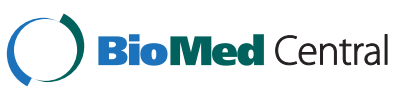

(C) 2014 Holt et al.; licensee BioMed Central Ltd. This is an Open Access article distributed under the terms of the Creative Commons Attribution License (http://creativecommons.org/licenses/by/4.0), which permits unrestricted use, distribution, and reproduction in any medium, provided the original work is properly credited. The Creative Commons Public Domain Dedication waiver (http://creativecommons.org/publicdomain/zero/1.0/) applies to the data made available in this article unless otherwise stated. 
Since its introduction in Australia in 2002, tenofovir disoproxil fumarate (TDF) has become the most widely used antiretroviral agent in HIV-infected patients and is listed as a preferred ART regimen in major guidelines [9-11]. Although preclinical studies and early clinical data did not identify any renal safety issues for TDF, a series of case reports and large population studies have suggested it has nephrotoxic potential in some HIVinfected patients, albeit with a low frequency [12-15]. Monitoring patients in order to pick up nephrotoxicity and proactive dose adjustment form part of routine HIV care. However, national and international guidelines lack detailed guidance for clinicians in the timing and nature of such monitoring (European AIDS Clinical Society [16] (EACS), British HIV Association [17] (BHIVA), US DHHS United States department of Health and Human Services [18]).

An expert panel convened by Gilead in Australia was set up to advise on the practical aspects of monitoring ART renal function in the absence of hard evidence. This took the form of a number of meetings where the evidence for nephrotoxity was sought and presented by various members of the panel (all of whom appear as authors of this paper) and based upon this a consensus monitoring algorithm was synthesised.

\section{Tenofovir}

The prodrug tenofovir disproxil fumarate (TDF) is given because tenofovir (TFV) has poor oral bioavailability, but once absorbed TDF is rapidly hydrolysed to TFV. TFV is a potent nucleotide analogue reverse transcriptase inhibitor with activity against HIV and hepatitis B virus (HBV). Circulating TFV is taken up by endocytosis in most cells (except in the renal tubule where specific transporters are present) and rapidly phosphorylated further forming a nucleoside analogue that causes chain termination in HIV reverse transcriptase or HBV DNA polymerase [19]. The volume of distribution is within total body water, and TFV is mainly renally excreted with little hepatic metabolism. Of note TFV excretion exceeds glomerular filtration rate (GFR), so tubular secretion is thought to contribute 20-30\% to its elimination.

A new formulation of TFV, tenofovir alafenamide (TAF, formerly GS-7340), is currently being evaluated in Phase III clinical trials. TAF is more stable in plasma and is predominantly hydrolysed to TFV intracellularly by cathepsin A in lymphocytes and macrophages. This results in high intracellular levels of the active phosphorylated tenofovir but reduced plasma levels of TFV. A recent phase II study showed significantly smaller changes in estimated creatinine clearance, renal tubular proteinuria than TDF [20].

\section{Evidence for renal effects}

In the early randomised controlled trials of TDF vs. thymidine analogues in HIV [21-23] and subsequent follow-up studies there were small but statistically insignificant differences in renal function but no signals suggesting nephrotoxicity [12,24-26]. However these studies involved relative healthy subjects and relied on measured changes in the serum creatinine ( $\mathrm{SCr}$ ). A series of case reports, predominantly of Fanconi syndrome started appearing in 2002 [27] and, propelled a re-examination of the renal safety data. The Viread Expanded Access Program [12] involving more than 10,000 people reported serious adverse renal events in 1.5 individuals per 1000 patientyears. Various cohort studies have subsequently reported associations between TDF exposure and small but statistically significant declines in estimated glomerular filtration rate (eGFR) over time. A recently published large cohort study of 22,603 HIV-infected persons [28] with a median follow up of 4.5 years (after 1January 2004) found that cumulative TDF, ritonavir-boosted atazanavir and ritonavir-boosted lopinavir use were all independent predictors of chronic renal impairment (confirmed eGFR of $\leq 70 \mathrm{~mL} / \mathrm{min}$ ) however, cumulative TDF use was not a significant predictor of CKD (eGFR of $\leq 60 \mathrm{~mL} / \mathrm{min}$ ). In a follow up publication expanded to over 35,000 patients with 200,119 person years of follow up $0.4 \%$ developed advanced renal failure $(\mathrm{eGFR}<30)$ and $0.06 \%$ developed end-stage renal failure [29]. Further, the data showed that whilst TDF was discontinued as GFR fell, current or previous drug use did not predict these outcomes and only traditional risk factors and CD4 count were associated with increased risk. In a meta-analysis of 11 studies [13] there was an estimated mean reduction in eGFR of $3.92 \mathrm{~mL} / \mathrm{min}$ among the TDF recipients compared with control subjects. Although this reduction was statistically significant, the magnitude was modest in clinical terms. This analysis also found no evidence that TDF use led to increased risk of CKD, severe proteinuria, hypophosphataemia or fractures. However, a large retrospective US cohort of 10,841 HIV-infected subjects [14] reported a small but significant increase in the relative risk of CKD (HR 1.44, 95\% CI 1.3-1.6) and proteinuria (HR 1.30, 1.22-1.37) with TDF exposure, that was greatest in those with more than 3 years of exposure suggesting that monitoring of renal function should continue long-term.

Labarga et al. [30] reported that over time, subclinical proximal tubular dysfunction can develop, involving relatively low level proteinuria and phosphaturia, but in the absence of an impaired GFR. This occurred in up to $22 \%$ of closely monitored HIV patients treated with TDF. It was interesting to note that tubular dysfunction was also seen in $12 \%$ of ART-naïve patients. Although this dysfunction did not appear to have clinical sequelae it is nevertheless of concern not only for renal function but also potentially for future bone health.

TDF is associated with Fanconi syndrome (proteinuria, hypokalaemia, hypophosphataemia, phosphaturia, 
aminoaciduria and glycosuria) or acute kidney injury (AKI). Based on the available data, the frequency of Fanconi syndrome/AKI associated with TDF in HIV-treat patients is $<1 \%[12,13]$. In the expanded access program, a serious adverse renal event of any type was observed in $0.5 \%$ of patients, with failure (acute and chronic) reported in $0.3 \%$ and Fanconi syndrome in $<0.1 \%$ [12]. In the metaanalysis the estimated increased risk of AKI was 0.7\% [13].

Importantly, in many cases the renal dysfunction is fully reversible, and if detected early more likely to do so whilst if ignored could lead to dialysis requirements. Jose et al. reports that if detected TDF toxicity appears reversible in around half of cases within a year but recovery can be prolonged and may continue for over 5 years [31]. In this study between $\sim 7-28 \%$ of patients did not fully recover, depending on the definition of full recovery. This study also showed that those with the largest change in GFR at discontinuation had a higher baseline GFR, and the duration of TDF treatment were the best determinants of incomplete recovery, making it important that initial and subsequent GFRs are recorded and compared [31]. No studies have fully addressed the concept of a TDF dose reduction in order to improve renal function and we do not endorse this strategy at present. Patients who have evidence of progressive nephrotoxicity, which only partially reverses with cessation of TDF, probably should not go back on this drug.

A South-African study has reported the association between nephrotoxicity (any decline in renal function from baseline) or death and baseline renal function [32]. They reported TDF nephrotoxicity in $2.4 \%$, and those at highest risk of death were those with pre-existing renal dysfunction. Those who were switched from other regimens onto a TDF-containing regimen were also at highest risk of nephrotoxicity.

\section{Pathophysiology of renal injury}

In the proximal tubules, high intracellular concentrations of TFV are thought to disrupt mitochondrial function affecting their number, size, shape and internal morphology [33]. TFV has a low inhibitory effect on mitochondrial DNA (mtDNA) polymerase- $\gamma$, which is important for mitochondrial replication. Depleted levels of mtDNA can lead to defects in electron transport chain function and oxidative phosphorylation causing a reduction in ATP generation and impaired energy production that may result in reduced resorptive capacity for ions and other molecules (e.g. phosphate and glucose), especially in the highly metabolically demanding and relatively hypoxic environment of the proximal tubule [34].

Although TFV is only a weak inhibitor of mtDNA $\gamma$ polymerase [35] the presence of a number of factors may combine to increase the risk of TFV tubulopathy in some HIV-infected individuals. Of note however, is the fact that the HIV virus itself causes mtDNA depletion, and this could be relevant when considering hypophosphataemia, including patients not on ART. TFV enters proximal tubular cells across the basolateral membrane via organic anion transporters (OAT1 and OAT3), and exits the tubule across the apical membrane via multidrug resistance protein transporters (MRP4 and possibly MRP2) coded for by the ABC cassette genes [36] (Figure 1). Co-administration of antiretroviral drugs that are also processed by these transporters (potentially affecting efflux) including ritonavir (MRP2) and didanosine (OAT1), have been implicated in many of the reports of TDF-related Fanconi syndrome. In a review of 164 cases received by the FDA Adverse Reporting System, 74\% of patients were also taking a ritonavir-boosted protease inhibitor and $43 \%$ were taking didanosine (now rarely used) [37].

Declining glomerular filtration due to age or co-existing CKD can result in a shift towards increased tubular secretion of TFV and other factors such as low body weight, may increase plasma TFV levels, have also be shown to be risk factors for TDF-related tubulopathy. Finally polymorphisms in genes associated with tubular transporter proteins may affect the flux of TFV into and out of proximal tubular and may help to explain why tubulopathy occurs in only some individuals, but this data is some way from being clinically useful [38-41].

\section{Cobicistat}

The inclusion of cobicistat in the recently introduced co-formulated tablet Stribild ${ }^{\bullet}$ (cobicistat + elvitegravir + emtricitabine $+\mathrm{TDF}$ ), adds an extra dimension to the renal monitoring in patients receiving this TDF-based single tablet regimen. Cobicistat, which has no intrinsic anti-HIV activity, is a potent cytochrome P450 3A (CYP3A) inhibitor and is used as a pharmacoenhancer to boost and maintain the therapeutic plasma concentration of the HIV integrase inhibitor elvitegravir over the 24-hour dosing interval. Cobicistat also reduces proximal tubular secretion of creatinine by inhibiting cation transporters (particularly MATE 1) in a manner similar to cimetidine or trimethoprim. This may have implications on other drug metabolism. It does however have the potential to interact with other drugs that are metabolised by CYP3A (e.g. azol anti-fungals, warfarin, salmeterol and some statins) or those excreted by MATE1 (metformin in particular) [42]. Cobicistat leads to a modest, rapid (days) and reversible, increase in $\mathrm{SCr}$, and therefore an apparent reduction in eGFR, but not GFR measured by iohexol clearance [43]. In the phase III registration studies (GS102/103) these studies involved $>1400$ treatment naïve patients followed to 144 weeks, the increase in $\mathrm{SCr}$ concentration (mean $\sim 12.4 \pm 11.5 \mu \mathrm{mol} / \mathrm{L}$ ) stabilised after $2-4$ weeks $^{76}$. This baseline change needs to be considered when monitoring renal function in patients receiving 


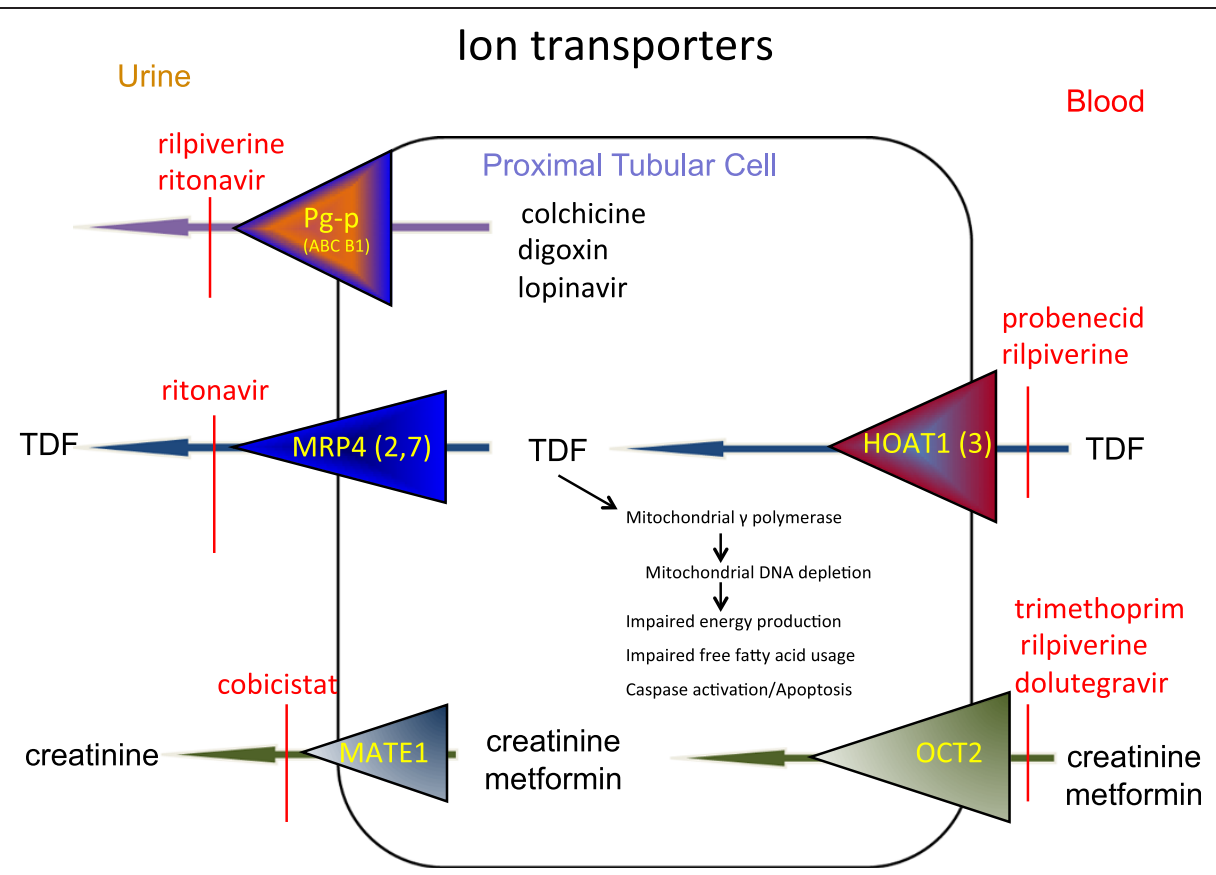

Figure 1 lon transporters involved in proximal tubular cell handling of creatinine and antiviral drugs.

cobicistat in combination therapy. We suggest that an immediate increase of $\mathrm{SCr}$ from baseline $<35 \mu \mathrm{mol} / \mathrm{L}$ (which is taken from the mean +2 SD of the Stribild trials) be considered a range that would capture $\sim 98 \%$ of the expected increases in patients with normal renal function and does not require additional investigation providing it is stable at this level.

\section{Rilpivirine}

Rilpivirine is a non-nucleoside reverse transcription inhibitor, which is minimally excreted by the kidney. A small increase in serum creatinine $(\sim 8.8 \mu \mathrm{mol} / \mathrm{L}=0.1 \mathrm{mg} / \mathrm{dL}$ in the TDF backbone regimen) has been noted in studies $[44,45]$ and it too has been shown to inhibit a number of transporters including the organic cation transporter protein 2 (OCT2) and p-glycoprotein (pg-p) [46].

The former inhibits tubular secretion of creatinine, as cystatin $\mathrm{C}$ measurements of renal function are unaffected. However cystatin $C$ based equations appear to be less accurate in patients with HIV taking ART $[47,48]$.

\section{Dolutegravir}

Dolutegravir is an HIV integrase inhibitor, again largely not excreted by the kidney and again inhibiting OCT2 [49] resulting in a small rise in creatinine (by $\sim 7.6 \mu \mathrm{mol} / \mathrm{L}$ in normal individuals [50]) without affecting GFR by iohexol clearance [51].

\section{Tenofovir in HBV}

Compared to the situation in HIV, the incidence of tubulopathy with TDF when used in chronic hepatitis B (HBV) appears to be lower, although two cases of reversible Fanconi Syndrome have recently been reported [52]. This may simply reflect ascertainment or reporting bias as experience of TDF use in HBV therapy is relatively small compared to use in HIV. However there may be key differences in the $\mathrm{HBV}$-infected compared to the $\mathrm{HIV}$-infected population, for example HIV-infected patients are more likely to be taking concomitant nephrotoxic drugs and, unlike HIV, the HBV does not appear itself to affect mitochondrial function [53]. In addition HBV is known to be associated with glomerulonephritis with [54], or without [55] evidence of viral replication which often responds to viral suppression and that may in fact improve renal function.

Reporting of renal function (eGFR, SCr and serum phosphate, but not proteinuria) in both the long-term follow-up of the TDF HBV clinical trials in abstract form (7 years to date) and at least five prospectively-followed cohorts of patients with chronic hepatitis B (both treatment-naïve and -experienced) have revealed generally fewer changes in creatinine despite the latter cohort having a number of risk factors for renal disease.

The European Association for the Study of the Liver (EASL) 2012 management guidelines recommend only that "Renal function should be monitored during antiviral treatment" [56]. Similarly the Asian Pacific consensus recommends "close observation on proximal tubular injury 
and bone toxicity must be maintained" [57]. In contrast the Gastroenterology Society Australia [58] and American Association for the Study of the Liver (AASLD) [59] suggests checking the serum creatinine every 12 weeks for patients on adefovir or tenofovir. Whilst awaiting further work in this area and since viral parameters are usually being measured 3-6 monthly, we encourage the addition of a serum creatinine estimation at these time points. However we feel it would be reasonable to check the same parameters (eGFR, plasma phosphate, uPCR and for glycosuria) at least yearly in patients on TDF.

\section{Renal monitoring}

In 2005, the Infectious Diseases Society of America recommended that all patients recently diagnosed with HIV infection should be screened for kidney abnormalities including SCr for calculation of eGFR and urinalysis dipstick for proteinuria, with annual screening for at-risk patients [60]. The more recent US DHHS suggest basic chemistry 3-6 monthly (Serum $\mathrm{Na}, \mathrm{K}, \mathrm{HCO}_{3}, \mathrm{Cl}, \mathrm{BUN}$, creatinine) and glucose (preferably fasting), with a suggestion that phosphorus levels should be taken in patients on TDF [18]. The more recent European AIDS Clinical Society guidelines recommend 3-12 monthly monitoring of eGFR and annual dipstick analysis for proteinuria with more frequent monitoring in high-risk groups for CKD. The Australasian Society for HIV Medicine commentary on the US DHHS guidelines recommends urinalysis (6 monthly) and electrolyte monitoring (including serum phosphate) in patients prescribed TDF in addition to routine renal monitoring of HIV-infected patients; again with more frequent monitoring in those with an increased risk of renal insufficiency.

\section{TDF HIV renal management algorithm}

Given the central role of TDF-based therapy and the potential for tubulopathy associated with TDF, we suggest active monitoring to maximise the drug's continued utility. These suggestions are outlined in the algorithm in Figure 2. It is important to note that this algorithm complements the Kidney Health Check $^{7}$ (SCr (and thus also eGFR), albumin/creatinine ratio (uACR) and blood pressure) recommended every 1-2 years for patients with diabetes, hypertension, obesity $(\mathrm{BMI} \geq 30)$, established CVD, smokers, those with a family history of CKD, and those of Aboriginal or Torres Strait Islander origin. This is in order to detect subclinical renal disease and to identify those patients with a higher cardiovascular risk or the small cohort who may go on to develop declining renal function. We suggest such monitoring is also appropriate for those who are on a non -TDF regimen. The key differences for patient on TDF based regimens is that urine total protein-to-creatinine ratio (uPCR) should be used, rather than $\mathrm{uACR}$, and the additional measurement of a serum phosphate level. The measurement of blood pressure is important for detecting cardiovascular and renal risk generally. Patients who may be at high risk of developing renal dysfunction include those;

- With co-infection with viral hepatitis

- Concomitant nephrotoxic medication (especially non-steroidal anti-inflammatory drugs (NSAID))

- With diabetes

- Who are Aboriginals, Torres Straight islanders or black Africans

- Who have a family history of renal disease

- With hypertension

- With pre-existing cardiovascular or renal disease

- With uncontrolled or untreated HIV

- With a low BMI $(<18.5)$

\section{GFR estimates}

In Australia, the Chronic Kidney Disease Epidemiology Collaboration (CKD-EPI) formula has largely replaced the Modification of Diet in Renal Disease (MDRD) equation for calculating eGFR [61]; CKD-EPI helps prevent underestimates of GFR particularly at the higher ranges of GFR [62]. Both equations have shown a reasonable degree of agreement in stratifying baseline eGFR in HIV positive population, although a recent publication suggests that CKD-EPI best approximates measured GFR in this group [63]. The differences between CKD-EPI eGFR and Cockcroft-Gault (CG) formula estimations of creatinine clearance are very modest (3.2 (IQR -0.6 to 7.4 $\left.\mathrm{mL} / \mathrm{Min} / 1.73 \mathrm{~m}^{2}\right)$ ) and typically have equal precision. Although recommendations for dose adjustment are typically quoted as creatinine clearance $(\mathrm{CrCl})$, we suggest using the CKD-EPI formula and in this context, and this can be used interchangeably with $\mathrm{CrCl}$ for TDF dose modification [64]. Cystatin $\mathrm{C}$ based equations cannot be recommended for renal monitoring in HIV positive individuals because its generation is affected by HIV itself and a number of antivirals $[47,48,65]$.

\section{Abnormal baseline tests}

If patients have abnormal test results at baseline, treatable reasons for kidney disease should be excluded and the patient's risk of CVD assessed and managed with lifestyle modification and medication, as appropriate, to control hypertension (ACE inhibitor or angiotensin II receptor blockers as first line therapy), dyslipidaemia and hyperglycaemia. Nephrotoxic medications should be avoided and medication doses adjusted for renal function. The prescriber should consider carefully the appropriateness of commencing TDF, which may require a dosing interval adjustment (as detailed in the product information) $^{75}$ in all patients with $\mathrm{CrCl} / \mathrm{eGFR}<50$ (see Table 1). Stribild should not be initiated in patients with 
Table 1 TDF dose reduction strategies

\begin{tabular}{ll}
\hline $\begin{array}{l}\text { Creatinine clearance } \\
\text { (or eGFR - CKD-EPI) }\end{array}$ & Dosing interval for TDF $\mathbf{3 0 0} \mathbf{~ m g}$ \\
\hline$>50$ & Every $24 \mathrm{hrs}$ \\
$30-49$ & Every 48 hrs* \\
$10-29$ & Every $72-96$ hrs $^{*}$ \\
Haemodialysis & After dialysis every 7 days or \\
& after $\sim 12$ hrs of dialysis* \\
\hline
\end{tabular}

${ }^{*}$ Consider whether TDF is the appropriate antiviral.

eGFR $/ \mathrm{CrCl}<70 \mathrm{~mL} / \mathrm{min} / 1.73 \mathrm{~m}^{2}$ and subsequently if the $\mathrm{CrCl}$ falls to $<50$, it should be discontinued because the required dose interval adjustments are not possible using this fixed dose combination tablet.

\section{Proteinuria}

A reduction in tubular ATP production may also allow enhanced urinary loss of low molecular weight proteins (e.g. ß2-microglobulin and retinol binding protein) which are usually freely filtered but reabsorbed by active processes involving megalin and cubilin. In contrast to glomerular disease, where large proteins such as albumin, are lost in the urine, the glomerular filtration barrier in TDF-associated renal injury is often relatively intact. This means that checking the urine for albumin alone (as recommended in the Kidney Health Australia (KHA) guidelines for detection of renal disease) may miss proteinuria due to tubular dysfunction. We recommend the use of UPCR since this will detect all urinary protein, not simply albumin. Thus glomerular disease (which may cause predominantly albuminuria) and/or tubular proteinuria (which may cause low molecular weight proteinuria) will both be detected if present [66]. A ratio of uACR to uPCR $<0.4$ has been suggested as a useful tool to distinguish between the two in HIV positive cohorts [67] and has been found to be helpful in determining the aetiology of proteinuria [68]. Dipstick urinalysis for protein is mainly sensitive to albumin, and especially in dilute urine may miss other (tubular) proteinuria [69].

\section{Glycosuria}

Any method for detecting urinary glucose is valid and a dipstick is a good test. If the patient is diabetic then the test should be performed with a blood glucose estimation to ensure normoglycaemia at the time of the test. Glycosuria is not normal under any circumstance (apart from pregnancy and the rare glucose transporter defects, or with patients on the new glut 2 inhibitors) [70]. Dipstick urinalysis is sensitive to glycosuria but can be negative in the face of high vitamin $C$ intake [69]. New glycosuria with normal serum glucose should warrant urgent repeat and if confirmed discontinuation of TDF.

\section{Serum phosphate}

Serum phosphate levels below the reference range can occur in diverse range of conditions including untreated HIV infection. Thus, the presence of hypophosphataemia should be confirmed on a fasting specimen and other potential causes investigated.

Moderate hypophosphataemia $(0.65-0.8 \mathrm{mmol} / \mathrm{L})$ is often transient, benign and of unknown significance. Follow up isolated hypophosphataemia would be onerous, expensive, and largely unhelpful, and simply warrants monitoring at the next routine visit with a morning fasting sample. However, if the serum phosphate falls below $0.65 \mathrm{mmol} / \mathrm{L}$, further investigation [71] may be appropriate particularly looking for features of Fanconi syndrome triad [72] (hypophosphataemia, glycosuria with normal serum glucose, mild proteinuria). Other biochemical features may include hypokalaemia, hypouricaemia, low serum bicarbonate, low serum urate. Clinical features may be polyuria and polydipsia, lassitude and bone pains.

Conditions associated with hypophosphataemia (adapted from [68]) include;

- alcohol excess

- concomitant drugs (e.g. antacids and phosphate binders, diuretics, bisphosphonates, corticosteroids)

- the Fanconi syndrome either inherited or acquired (e.g. cisplatinum, ifosphamide, antivirals)

- rare syndromes associated with FGF23 excess inherited (e.g. X-linked hypophosphataemia) or acquired (e.g. tumour induced osteomalacia), iron infusion

- a glucose or insulin load

- those with hepatic impairment

- primary hyperparathyroidism

- malabsorption syndromes

- a respiratory alkalosis (hyperventilation)

- untreated HIV

\section{Reasons for nephrology referral}

If the Fanconi syndrome is confirmed then TDF should be stopped and the patient changed to a non-TDF containing ARV regimen, and renal function and proteinuria followed carefully with monthly testing until these features have resolved. If no improvements in these abnormalities are apparent within a month then a nephrological review is strongly recommended. Other situations when referral to a nephrologist with an interest in HIV or specialist HIV physician include:

- $\mathrm{eGFR}<30 \mathrm{~mL} / \mathrm{min}$

- Ongoing significant proteinuria (uPCR $>50 \mathrm{mg} / \mathrm{mmol}$ )

- A consistent decline in eGFR from baseline $<60 \mathrm{~mL} / \mathrm{min}$ (i.e. decline $>5 \mathrm{~mL} / \mathrm{min}$ over a 6 -month period, confirmed $\geq 3$ separate readings) 


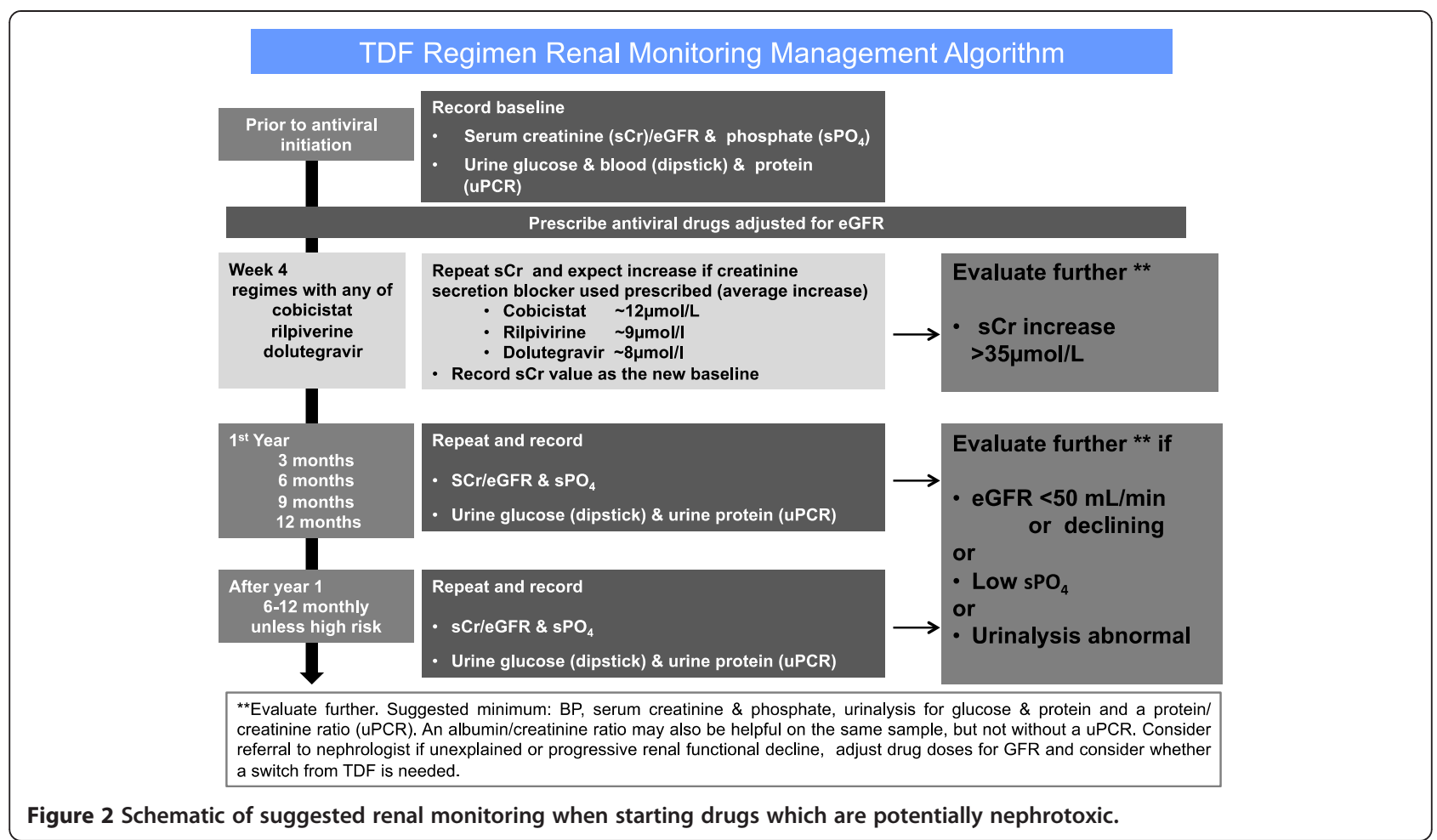

- Glomerular haematuria with albuminuria

- CKD and difficult to control hypertension despite $\geq 3$ antihypertensive agents

- Microscopic or macroscopic haematuria alone should also be referred for urine cytology, imaging and possibly cystoscopy.

If renal dysfunction is not related to a full Fanconi syndrome, but thought to be related to TDF, then a prompt switch away from TDF-based antivirals is almost always the best choice. However, it is our observation is that this switch is sometimes made where the evidence implicating TDF for the renal decline is scarce or non-existent, and often without considering alternative diagnoses. The implications are that TDF is then unavailable for future use in that individual, which significantly narrows the antiviral regimen choice. Thus the decision to stop a regimen, which is usually successfully supressing virus, is not a trivial one and should be made by weighing the evidence implicating a particular drug in the renal decline.

\section{Frequency of follow up}

Most international guidelines suggest at least yearly follow up of renal function, which we consider the minimum frequency for good care of patients with HIV-infection. Some authors advocate testing 3 monthly in the first year and yearly thereafter [73], as those who are well with completely normal tests in the first
12 months appear to be at lower risk of nephrotoxicity. The data for TDF suggest that the risk of nephrotoxicity may increase over time in at-risk patients [14]. We therefore suggest more frequent (3-6 monthly) review of patients with identified renal disease (e.g. CKD, mild proteinuria or hypophosphatemia but without glycosuria) particularly when a dose adjustment may be needed (Figure 2). Any patient with the Fanconi syndrome should be re-tested monthly until there are improvements in biochemistry and then every 3 months until back to baseline function and referred for specialist review by an HIV physician or a nephrologist with an interest in HIV. We feel it would be sensible for high risk-patients on TDF for HBV mono-infection infection to have similar renal investigations at least yearly. Patients who are not on nephrotoxic antiviral agents may still be at higher risk of developing renal dysfunction associated with non drug related issues and ageing. Thus a yearly Kidney Health Check [7] would appear be appropriate in these patients.

\section{Competing interests}

SGH has received research funding or honoraria for services from Amgen, Baxter, Gilead, Novartis and Shire. DG has been an advisory board member for Gilead and has been in receipt of honoraria for presentations for Gilead, MSD and ViiV Healthcare and has been in receipt of travel grant support from Gilead. MTL has received research funding and or honoraria from Gilead, Bristol Myers Squibb and Roche. RA is employed by Gilead Sciences. $M B$ has received grant funding for research projects from Merck, Abbvie and Gilead, and has been in receipt of honoraria for serving on HIV Advisory Boards for Merck and Gilead in addition to receiving honoraria for acting as a consultant, chairing meetings and/or preparation and delivery of 
educational materials from AbbVie, Bristol Myers Squibb, Boehringer Ingelheim, Gilead, Janssen-Cilag and Merck. All other authors have received honoraria from Gilead to attend meetings to discuss this topic but declare no other conflicts of interest.

\section{Authors' contributions}

All authors contributed equally to the discussions and agreements around key decision points. The consensus document was primarily put together by SGH with help from DG, MAB, ML and RA and subsequently reviewed and agreed by the other authors. All authors read and approved the final manuscript.

\section{Author details}

'The Royal Melbourne Hospital and Faculty of Medicine University of Melbourne, 300 Grattan St, Parkville, Melbourne, VIC 3050, Australia. ${ }^{2}$ Royal Prince Alfred Hospital and Central Clinical School, Faculty of Medicine, University of Sydney, Missenden Rd, Camperdown, NSW 2050, Australia. ${ }^{3}$ Liverpool Hospital, Elizabeth St, Liverpool, NSW 2170, Australia. ${ }^{4}$ Princess Alexandra Hospital, 199 Ipswich Road, Woolloongabba, QLD 4102, Australia. ${ }^{5}$ Royal Perth Hospital, 197 Wellington St, Perth, WA 6000, Australia. ${ }^{6}$ Alfred Hospital, and Department of Medicine, Monash University, Melbourne, VIC 3004, Australia. ${ }^{7}$ Cairns Base Hospital, 165 The Esplanade, Cairns, QLD 4870, Australia. ${ }^{8}$ St. Vincent's Hospital, 390 Victoria Street, Darlinghurst NSW 2010, Australia. ${ }^{9}$ Medical Affairs, Gilead Sciences, Level 6, 417 St Kilda Road, Melbourne VIC 3004, Australia. ${ }^{10}$ Kirby Institute, UNSW, Sydney, NSW 2052، Australia

Received: 8 April 2014 Accepted: 6 September 2014 Published: 10 November 2014

\section{References}

1. McManus H, O'Connor CC, Boyd M, Broom J, Russell D, Watson K, Roth N, Read PJ, Petoumenos K, Law MG: Long-term survival in HIV positive patients with up to 15 Years of antiretroviral therapy. PLoS One 2012, 7:e48839.

2. Post FA, Holt SG: Recent developments in HIV and the kidney. Curr Opin Infect Dis 2009, 22:43-48.

3. Ando M, Tsuchiya K, Nitta K: How to manage HIV-infected patients with chronic kidney disease in the HAART era. Clin Exp Nephrol 2012, 16:363-372.

4. Rasch MG, Helleberg M, Feldt-Rasmussen B, Kronborg G, Larsen CS, Pedersen C, Pedersen G, Gerstoft J, Obel N: Increased risk of dialysis and end-stage renal disease among HIV patients in Denmark compared with the background population. Nephrol Dial Transplant 2013, 29(6):1232-1238.

5. Islam FM, Wu J, Jansson J, Wilson DP: Relative risk of renal disease among people living with HIV: a systematic review and meta-analysis. BMC Public Health 2012, 12:234

6. Roe J, Campbell L, Ibrahim F, Hendry BM, Post FA: HIV care and the incidence of acute renal failure. Clin Infect Dis 2008, 47:242-249.

7. Kidney Health Australia: Chronic Kidney Disease Management in General Practice. [http://www.kidney.org.au/HealthProfessionals/ CKDManagementinGeneralPractice/tabid/789/Default.aspx]

8. Gracey D, Chan D, Bailey M, Richards D, Dalton B: Screening and management of renal disease in human immunodeficiency virus-infected patients in Australia. Intern Med J 2013, 43:410-416.

9. Thompson MA, Aberg JA, Cahn P, Montaner JSG, Rizzardini G, Telenti A, Gatell JM, Günthard HF, Hammer SM, Hirsch MS, Jacobsen DM, Reiss P, Richman DD, Volberding PA, Yeni P, Schooley RT: Antiretroviral treatment of adult HIV infection: 2010 recommendations of the International AIDS Society-USA panel. JAMA 2010, 304:321-333.

10. Boyd SD: Management of HIV infection in treatment-naive patients: a review of the most current recommendations. Am J Health Syst Pharm 2011, 68:991-1001

11. Doherty M, Ford N, Vitoria M, Weiler G, Hirnschall G: The 2013 WHO guidelines for antiretroviral therapy: evidence-based recommendations to face new epidemic realities. Curr Opin HIV AIDS 2013, 8:528-534

12. Nelson MR, Katlama C, Montaner JS, Cooper DA, Gazzard B, Clotet B, Lazzarin A, Schewe K, Lange J, Wyatt C, Curtis S, Chen S, Smith S, Bischofberger N, Rooney JF: The safety of tenofovir disoproxil fumarate for the treatment of HIV infection in adults : the first 4 years. AIDS 2007, 21:1273-1281.
13. Cooper RD, Wiebe N, Smith N, Keiser P, Naicker S, Tonelli M: Systematic review and meta-analysis: renal safety of tenofovir disoproxil fumarate in HIV-infected patients. Clin Infect Dis 2010, 51:496-505.

14. Scherzer R, Estrella M, Li Y, Deeks SG, Grunfeld C, Shlipak MG: Association of tenofovir exposure with kidney disease risk in HIV infection. AIDS 2012, 26:1273-1281

15. Msango L, Downs JA, Kalluvya SE, Kidenya BR, Kabangila R, Johnson WD, Fitzgerald DW, Peck RN: Renal dysfunction among HIV-infected patients starting antiretroviral therapy. AIDS 2011, 25:1421-1425.

16. Clumeck N, Pozniak A, Raffi F: European AIDS Clinical Society (EACS) guidelines for the clinical management and treatment of HIV-infected adults. HIV Med 2008, 9:65-71.

17. Williams I, Churchill D, Anderson J, Boffito M, Bower M, Cairns G, Cwynarsk K, Edwards S, Fidler S, Fisher M, Freedman A, Geretti AM, Gilleece Y, Horne R, Johnson M, Khoo S, Leen C, Marshall N, Nelson M, Orkin C, Paton N, Phillips A, Post F, Pozniak A, Sabin C, Trevelion R, Ustianowski A, Walsh J, Waters L, Wilkins E, et al: British HIV Association guidelines for the treatment of HIV-1-positive adults with antiretroviral therapy 2012 (Updated November 2013. All changed text is cast in yellow highlight.). HIV Med 2014, 15 Suppl 1(July 2012):1-85.

18. HIV/AIDS Guidelines - adultandadolescentgl.pdf. [http://aidsinfo.nih.gov/ contentfiles/lvguidelines/adultandadolescentgl.pdf]

19. Antoniou T, Park-Wyllie LY, Tseng AL: Tenofovir: a nucleotide analog for the management of human immunodeficiency virus infection. Pharmacotherapy 2003, 23:29-43.

20. Sax PE, Zolopa A, Brar I, Elion R, Ortiz R, Post F, Wang H, Callebaut C, Martin H, Fordyce MW, McCallister S: Tenofovir Alafenamide vs. Tenofovir Disoproxil Fumarate in Single Tablet Regimens for Initial HIV-1 Therapy: A Randomized Phase 2 Study. J Acquir Immune Defic Syndr 2014, 67(1):52-58.

21. Gallant JE, Staszewski S, Pozniak AL, DeJesus E, Suleiman JMAH, Miller MD, Coakley DF, Lu B, Toole JJ, Cheng AK: Efficacy and safety of tenofovir DF vs stavudine in combination therapy in antiretroviral-naive patients: a 3-year randomized trial. JAMA 2004, 292:191-201.

22. Gallant JE, Winston JA, DeJesus E, Pozniak AL, Chen S-S, Cheng AK, Enejosa $\mathrm{JV}$ : The 3-year renal safety of a tenofovir disoproxil fumarate vs. a thymidine analogue-containing regimen in antiretroviral-naive patients. AIDS 2008, 22:2155-2163.

23. Gallant JE, DeJesus E, Arribas JR, Pozniak AL, Gazzard B, Campo RE, Lu B, McColl D, Chuck S, Enejosa J, Toole JJ, Cheng AK: Tenofovir DF, emtricitabine, and efavirenz vs. zidovudine, lamivudine, and efavirenz for HIV. N Engl J Med 2006, 354:251-260.

24. Izzedine H, Hulot JS, Vittecoq D, Gallant JE, Staszewski S, Launay-Vacher V, Cheng A, Deray G: Long-term renal safety of tenofovir disoproxil fumarate in antiretroviral-naive HIV-1-infected patients. Data from a double-blind randomized active-controlled multicentre study. Nephrol Dial Transplant 2005, 20:743-746.

25. Gallant JE, Moore RD: Renal function with use of a tenofovir-containing initial antiretroviral regimen. AIDS 2009, 23:1971-1975.

26. Cassetti I, Madruga JVR, Suleiman JMAH, Etzel A, Zhong L, Cheng AK, Enejosa J: The safety and efficacy of tenofovir DF in combination with lamivudine and efavirenz through 6 years in antiretroviral-naïve HIV-1infected patients. HIV Clin Trials 2007, 8:164-172.

27. Verhelst D, Monge M, Meynard J-L, Fouqueray B, Mougenot B, Girard P-M, Ronco $P$, Rossert J: Fanconi syndrome and renal failure induced by tenofovir: a first case report. Am J Kidney Dis 2002, 40:1331-1333.

28. Ryom L, Mocroft A, Kirk O, Worm SW, Kamara DA, Reiss P, Ross M, Fux CA, Morlat P, Moranne O, Smith C, Lundgren JD: Association between antiretroviral exposure and renal impairment among HIV-positive persons with normal baseline renal function: the D:A:D study. J Infect Dis 2013, 207:1359-1369.

29. Ryom L, Mocroft A, Kirk O, Ross M, Reiss P, Fux CA, Morlat P, Moranne O, Smith C, El-Sadr W, Law M, Lundgren JD: Predictors of advanced chronic kidney disease and end-stage renal disease in HIV-positive persons. AIDS 2014, 28:187-199.

30. Labarga P, Barreiro P, Martin-carbonero L, Solera C, Medrano J, Rivas P, Albalater M, Blanco F, Moreno V, Vispo E, Soriano V: Kidney tubular abnormalities in the absence of impaired glomerular function in HIV patients treated with tenofovir. AIDS 2009, 23:689-696.

31. Jose S, Hamzah L, Campbell L, Hill T, Fisher M, Leen C, Gilson R, Walsh J, Nelson M, Hay P, Johnson M, Chadwick D, Nitsch D, Jones R, Sabin C, Post F: Incomplete reversibility of eGFR following tenofovir exposure. $J$ Infect Dis 2014, 210(3):363-373. 
32. Brennan A, Evans D, Maskew M, Naicker $S$, Ive $P$, Sanne I, Maotoe T, Fox M: Relationship between renal dysfunction, nephrotoxicity and death among HIV adults on tenofovir. AIDS 2011, 25:1603-1609.

33. Herlitz LC, Mohan S, Stokes MB, Radhakrishnan J, D'Agati VD, Markowitz GS: Tenofovir nephrotoxicity: acute tubular necrosis with distinctive clinical pathological, and mitochondrial abnormalities. Kidney Int 2010, 78:1171-1177

34. Perazella MA: Tenofovir-induced kidney disease: an acquired renal tubular mitochondriopathy. Kidney Int 2010, 78:1060-1063.

35. Birkus G, Hitchcock MJM, Cihlar T: Assessment of mitochondrial toxicity in human cells treated with tenofovir: comparison with other nucleoside reverse transcriptase inhibitors. Antimicrob Agents Chemother 2002, 46:716-723.

36. Fernandez-Fernandez B, Montoya-Ferrer A, Sanz AB, Sanchez-Niño MD, Izquierdo MC, Poveda J, Sainz-Prestel V, Ortiz-Martin N, Parra-Rodriguez A, Selgas R, Ruiz-Ortega M, Egido J, Ortiz A: Tenofovir nephrotoxicity: 2011 update. AIDS Res Treat 2011, 2011:354908.

37. Gupta SK: Tenofovir-associated Fanconi syndrome: review of the FDA adverse event reporting system. AIDS Patient Care STDS 2008, 22:99-103.

38. Rodriguez-Novoa S, Labarga P, Soriano V: Pharmacogenetics of tenofovir treatment. Pharmacogenomics 2009, 10:1675-1685.

39. Pushpakom SP, Liptrott NJ, Rodríguez-Nóvoa S, Labarga P, Soriano V, Albalater M, Hopper-Borge E, Bonora S, Di Perri G, Back DJ, Khoo S, Pirmohamed M, Owen A: Genetic variants of ABCC10, a novel tenofovir transporter, are associated with kidney tubular dysfunction. J Infect Dis 2011, 204:145-153.

40. Izzedine H, Hulot J-S, Villard E, Goyenvalle C, Dominguez S, Ghosn J, Valantin MA, Lechat P, Deray AG: Association between ABCC2 gene haplotypes and tenofovir-induced proximal tubulopathy. J Infect Dis 2006 194:1481-1491.

41. Nishijima T, Gatanaga H, Komatsu H, Tsukada K, Shimbo T, Aoki T, Watanabe K, Kinai E, Honda H, Tanuma J, Yazaki H, Honda M, Teruya K, Kikuchi Y, Oka S: Renal function declines more in tenofovir- than abacavir-based antiretroviral therapy in low-body weight treatment-naïve patients with HIV infection. PLoS One 2012, 7:e29977.

42. Toyama K, Yonezawa A, Masuda S, Osawa R, Hosokawa M, Fujimoto S, Inagaki N, Inui K, Katsura T: Loss of multidrug and toxin extrusion 1 (MATE1) is associated with metformin-induced lactic acidosis. $\mathrm{Br} J$ Pharmacol 2012, 166:1183-1191.

43. German P, Liu HC, Szwarcberg J, Hepner M, Andrews J, Kearney BP, Mathias A: Effect of cobicistat on glomerular filtration rate in subjects with normal and impaired renal function. J Acquir Immune Defic Syndr 2012, 61:32-40.

44. Cohen CJ, Molina J-M, Cahn P, Clotet B, Fourie J, Grinsztejn B, Wu H, Johnson MA, Saag M, Supparatpinyo K, Crauwels H, Lefebvre E, Rimsky LT, Vanveggel S, Williams $P$, Boven K: Efficacy and safety of rilpivirine (TMC278) versus efavirenz at 48 weeks in treatment-naive HIV-1-infected patients: pooled results from the phase 3 double-blind randomized ECHO and THRIVE Trials. J Acquir Immune Defic Syndr 2012, 60:33-42.

45. Cohen CJ, Molina J-M, Cassetti I, Chetchotisakd P, Lazzarin A, Orkin C, Rhame F, Stellbrink H-J, Li T, Crauwels H, Rimsky L, Vanveggel S, Williams P, Boven K: Week 96 efficacy and safety of rilpivirine in treatment-naive, HIV-1 patients in two Phase III randomized trials. AIDS 2013, 27:939-950.

46. Moss DM, Liptrott NJ, Curley P, Siccardi M, Back DJ, Owen A: Rilpivirine inhibits drug transporters $A B C B 1, S L C 22 A 1$, and SLC22A2 in vitro. Antimicrob Agents Chemother 2013, 57:5612-5618.

47. Bhasin B, Lau B, Atta MG, Fine DM, Estrella MM, Schwartz GJ, Lucas GM: HIV viremia and T-cell activation differentially affect the performance of glomerular filtration rate equations based on creatinine and cystatin C. PLoS One 2013, 8:e82028

48. Barraclough K, Er L, Ng F, Harris M, Montaner J, Levin A: A comparison of the predictive performance of different methods of kidney function estimation in a well-characterized HIV-infected population. Nephron Clin Pract 2009, 111:c39-c48.

49. Reese MJ, Savina PM, Generaux GT, Tracey H, Humphreys JE, Kanaoka E, Webster LO, Harmon KA, Clarke JD, Polli JW: In vitro investigations into the roles of drug transporters and metabolizing enzymes in the disposition and drug interactions of dolutegravir, a HIV integrase inhibitor. Drug Metab Dispos 2013, 41:353-361.

50. Raffi F, Rachlis A, Stellbrink H-J, Hardy WD, Torti C, Orkin C, Bloch M, Podzamczer D, Pokrovsky V, Pulido F, Almond S, Margolis D, Brennan C,
Min S: Once-daily dolutegravir versus raltegravir in antiretroviral-naive adults with HIV-1 infection: 48 week results from the randomised double-blind, non-inferiority SPRING-2 study. Lancet 2013, 381:735-743.

51. Koteff J, Borland J, Chen S, Song I, Peppercorn A, Koshiba T, Cannon C, Muster H, Piscitelli SC: A phase 1 study to evaluate the effect of dolutegravir on renal function via measurement of iohexol and para-aminohippurate clearance in healthy subjects. Br J Clin Pharmacol 2013, 75:990-996.

52. Gracey DM, Snelling P, McKenzie P, Strasser SI: Tenofovir-associated Fanconi syndrome in patients with chronic hepatitis B monoinfection. Antivir Ther 2013, 18(7):945-948.

53. Berg T, Zoulim F, Moeller B, Trinh H, Marcellin P, Chan S, Kitrinos KM, Dinh P Flaherty JF Jr, McHutchison JG, Manns M: Long-term efficacy and safety of emtricitabine plus tenofovir DF vs tenofovir DF monotherapy in adefovir-experienced chronic hepatitis B patients. J Hepatol 2013, 60(4):715-722

54. Tang S, Lai FM-M, Lui YH, Tang CSO, Kung NNS, Ho YW, Chan KW, Leung JCK, Lai KN: Lamivudine in hepatitis B-associated membranous nephropathy. Kidney Int 2005, 68:1750-1758.

55. Das P, Vivek V, Ford M, Kingdon E, Holt S: Hepatitis B virus related membranous glomerulonephritis and proteinuria treated with lamivudine and tenofovir. Case Reports 2011. doi: 10.1136/bcr.05.2011.4287.

56. European Association For the Study of The Liver (EASL): EASL clinical practice guidelines: Management of chronic hepatitis B virus infection. J Hepatol 2012, 57:167-185

57. Liaw Y-F, Kao J-H, Piratvisuth T, Chan HLY, Chien R-N, Liu C-J, Gane E, Locarnini S, Lim S-G, Han K-H, Amarapurkar D, Cooksley G, Jafri W, Mohamed R, Hou J-L, Chuang W-L, Lesmana LA, Sollano JD, Suh D-J, Omata M: Asian-Pacific consensus statement on the management of chronic hepatitis B: a 2012 update. Hepatol Int 2012, 6:531-561.

58. Chronic Hepatitis B Recommendations - Australia and New Zealand (2010). [www.gesa.org.au/professional.asp?cid=9\&id=109]

59. Lok ASF, Mcmahon BJ: AASLD PRACTICE GUIDELINES Chronic Hepatitis B: Update 2009. Hepatology 2009, 50:15-17.

60. Gupta SK, Eustace JA, Winston JA, Boydstun II, Ahuja TS, Rodriguez RA, Tashima KT, Roland M, Franceschini N, Palella FJ, Lennox JL, Klotman PE, Nachman SA, Hall SD, Szczech LA: Guidelines for the management of chronic kidney disease in HIV-infected patients: recommendations of the HIV Medicine Association of the Infectious Diseases Society of America. Clin Infect Dis 2005, 40:1559-1585.

61. Johnson DW, Jones GRD, Mathew TH, Ludlow MJ, Doogue MP, Jose MD, Langham RG, Lawton PD, McTaggart SJ, Peake MJ, Polkinghorne K, Usherwood T: Chronic kidney disease and automatic reporting of estimated glomerular filtration rate: new developments and revised recommendations. Med J Aust 2012, 197:224-225.

62. Matsushita K, Mahmoodi BK, Woodward M, Emberson JR, Jafar TH, Jee SH, Polkinghorne KR, Shankar A, Smith DH, Tonelli M, Warnock DG, Wen C-P, Coresh J, Gansevoort RT, Hemmelgarn BR, Levey AS: Comparison of risk prediction using the CKD-EPI equation and the MDRD study equation for estimated glomerular filtration rate. JAMA 2012, 307:1941-1951.

63. Okparavero AA, Tighiouart $H$, Krishnasami Z, Wyatt CM, Graham H, Hellinger J, Inker LA: Use of glomerular filtration rate estimating equations for drug dosing in HIV-positive patients. Antivir Ther 2013, 18:793-802.

64. Mocroft A, Ryom L, Reiss P, Furrer H, D'Arminio Monforte A, Gatell J, de Wit S, Beniowski M, Lundgren J, Kirk O: A comparison of estimated glomerular filtration rates using Cockcroft-Gault and the Chronic Kidney Disease Epidemiology Collaboration estimating equations in HIV infection. HIV Med 2014, 15:144-152.

65. Gagneux-Brunon A, Mariat C, Delanaye P: Cystatin C in HIV-infected patients: promising but not yet ready for prime time. Nephrol Dial Transplant 2012, 27:1305-1313.

66. Smith ER, Ming M, Cai X, McMahon LP, Wright DA, Holt SG, Cai MMX: The value of simultaneous measurements of urinary albumin and total protein in proteinuric patients. Nephrol Dial Transplant 2012, 27:1534-1541.

67. Samarawickrama A, Cai M, Smith ER, Nambiar K, Sabin C, Fisher M, Gilleece $Y$, Holt SG: Simultaneous measurement of urinary albumin and total protein may facilitate decision-making in HIV-infected patients with proteinuria. HIV Med 2012, 13:1-7.

68. Reynes J, Cournil A, Peyriere H, Psomas C, Guiller E, Chatron M, Cristol J-P, Badiou S: Tubular and glomerular proteinuria in HIV-infected adults with estimated glomerular filtration rate $\geq 60 \mathrm{ml} / \mathrm{min} / 1.73 \mathrm{~m} 2$. AIDS 2013 , 27:1295-1302. 
69. Fogazzi GB, Verdesca S, Garigali G: Urinalysis: core curriculum 2008. Am J Kidney Dis 2008, 51:1052-1067.

70. Wright EM, Loo DDF, Hirayama BA: Biology of human sodium glucose transporters. Physiol Rev 2011, 91:733-794

71. Asboe D, Aitken C, Boffito M, Booth C, Cane P, Fakoya A, Geretti AM, Kelleher P, Mackie N, Muir D, Murphy G, Orkin C, Post F, Rooney G, Sabin C Sherr L, Smit E, Tong W, Ustianowski A, Valappil M, Walsh J, Williams M, Yirrell D: British HIV Association guidelines for the routine investigation and monitoring of adult HIV-1-infected individuals 2011. HIV Med 2012, 13:1-44.

72. Izzedine H, Launay-Vacher V, Isnard-Bagnis C, Deray G: Drug-induced Fanconi's syndrome. Am J Kidney Dis 2003, 41:292-309.

73. Hall AM, Hendry BM, Nitsch D, Connolly JO: Tenofovir-associated kidney toxicity in HIV-infected patients: a review of the evidence. Am J Kidney Dis 2011, 57:773-780.

doi:10.1186/1742-6405-11-35

Cite this article as: Holt et al:: A consensus statement on the renal monitoring of Australian patients receiving tenofovir based antiviral therapy for HIV/HBV infection. AIDS Research and Therapy 2014 11:35.

\section{Submit your next manuscript to BioMed Central and take full advantage of:}

- Convenient online submission

- Thorough peer review

- No space constraints or color figure charges

- Immediate publication on acceptance

- Inclusion in PubMed, CAS, Scopus and Google Scholar

- Research which is freely available for redistribution 